\title{
Breeding birds actively modify the initial microclimate of occupied tree cavities
}

\author{
Marta Maziarz ${ }^{1,2}$ (D)
}

Received: 2 August 2018 / Revised: 18 October 2018 / Accepted: 3 December 2018 / Published online: 28 January 2019

(C) The Author(s) 2019

\begin{abstract}
The microclimate of cavities used by endothermic animals may depend on dynamic relationships between a cavity's physical properties and the heating activity of cavity users, but the rudiments of these relationships are unclear. I compared the temperature and relative humidity of active tree cavities that were occupied by nesting marsh tits Poecile palustris with the conditions in vacant tree cavities previously used for breeding by this species. I tested how presence of active nests modified initial cavity microclimate, and if this modification changed with nest progression or cavity insulation. In 2013-2014, mean daily internalambient temperature differences averaged $1.5-4.1^{\circ} \mathrm{C}$ higher and relative humidity $8-10 \%$ lower, in active cavities relative to vacant sites, with greatest differences in the late nestling period. Compared to vacant cavities and relative to respective ambient values, the greatest daily minimum temperature increase was in active cavities located in the thinnest trees, which insulated least efficiently. As daily minimum temperatures were elevated to a similar level relative to outside within all active cavities, birds appeared to compensate for heat loss from cavities by warming the air within in a homeostatic manner. Similar to vacant cavities, the differences between daily maximum internal and ambient temperatures decreased with tree girth in active cavities, indicating that daily temperature maxima were systematically moderated in the thickest trees. The study demonstrates the modifying effect of birds' breeding activity on tree-cavity microclimate and highlights the role of a cavity's thermal properties in reducing the energy expenditure and risk of overheating for cavity users.
\end{abstract}

Keywords Białowieża Forest $\cdot$ Air temperature $\cdot$ Relative humidity $\cdot$ Cavity users $\cdot$ Nest sites

\section{Introduction}

Protection against harmful weather conditions is essential for survival and successful reproduction in endothermic animals, including birds. Such protection can be provided by tree cavities, which are used by many birds and mammals for nesting or roosting (Gibbons and Lindenmayer 2002). However, some cavities can be more efficient insulators than others in buffering against severe ambient conditions, depending on the dimensions and location in a tree (e.g. Wiebe 2001; Paclík and Weidinger 2007; Isaac et al. 2008; Coombs et al. 2010; Maziarz et al. 2017; Vierling et al. 2018). Consequently,

Marta Maziarz

mart.ann.maz@gmail.com

1 Laboratory of Forest Biology, Wrocław University, Sienkiewicza 21, 50335 Wrocław, Poland

2 Museum and Institute of Zoology, Polish Academy of Sciences, Wilcza 64, 00679 Warsaw, Poland diverse tree cavities might provide a wide range of microclimates for their potential occupiers, which may be able to discriminate and choose those with the most suitable conditions.

Utilising places that buffer well from extreme ambient temperatures and limit excessive heat exchange with the external environment can be beneficial for cavity-nesting birds, due to a lower risk of overheating (reviewed in Maziarz et al. 2017) or reduced energetic costs of thermoregulation (e.g. O'Connor 1975; Walsberg and King 1978; Haftorn and Reinertsen 1985). Additionally, moderate humidity inside nest sites might inhibit harmful excessive water loss and prevent dehydration of young birds (Deeming 2011; Mersten-Katz et al. 2012; Salaberria et al. 2014). Therefore, occupying cavities with moderately humid microclimates, well buffered from conditions outside, could give birds a selective advantage and so should be preferred by them.

The initial cavity microclimate that animals meet when selecting their nest sites may differ from the conditions experienced over the full duration of the nesting period. By building well-insulating nests and/or generating heat inside 
cavities, birds (and other endothermic animals) might elevate internal air temperatures relative to outside, and lower the relative humidity (Havera 1979; Willis and Brigham 2007; Maziarz and Wesołowski 2013; Griffiths et al. 2017; Rowland et al. 2017). In birds, this 'heating effect' might increase with the progression of nesting, from the incubation period when the air in a cavity is warmed by a single parent brooding eggs, to the late nestling period when several large chicks are present (Mersten-Katz et al. 2012; Maziarz and Wesołowski 2013).

Moreover, the amount of heat generated by endothermic animals and retained inside cavities might differ between sites, with presumably greater amount of heat retained in those that insulate more efficiently, i.e. more effectively reduce heat loss from inside (Kearney et al. 2011; Larson et al. 2018). Thus, the microclimate of occupied cavities might depend on a combination of ambient temperature, cavity insulation and the heating activity of endothermic occupants. Determining the relationships between these elements would be useful to assess the actual costs associated with the utilisation of different types of cavities by endothermic animals and to better understand the drivers of non-random cavity occupation.

The current study presents the microclimate, comprising air temperature and relative humidity, of tree cavities used for nesting by the marsh tit Poecile palustris - a small (c. $12 \mathrm{~g}$ ) altricial passerine that nests in pre-existing tree cavities (Cramp and Perrins 1993). I aimed to determine (1) how presence of an active nest modifies the initial tree-cavity microclimate, (2) if the degree of modification of the tree-cavity microclimate by nesting birds increases with nest progression from the incubation to the late nestling period and (3) if the heating effect of the birds' breeding activity depends on cavity insulation that varies with internal dimensions and location in a tree. For this purpose, I characterised the microclimate of 'active cavities', i.e. those occupied by nesting marsh tits, and compared it with the microclimate of 'vacant cavities' that had previously been used for breeding by this species but remained empty during the study.

Marsh tits typically occupy cavities that are situated relatively low above the ground, in rather thin and almost always living tree trunks in mature forest; their typical nest cavities have a narrow entrance, small floor area and a moderate depth (e.g. Wesołowski 1996; Broughton et al. 2011).

It was previously shown that air temperatures inside vacant cavities used by marsh tits depend on ambient values, but the daily pattern of temperature change inside these tree cavities differs from outside. In contrast, the relative humidity is stable despite strongly fluctuating ambient values (Maziarz et al. 2017). I presumed that similar patterns of change in temperature and humidity would be present in active cavities used by nesting marsh tits, but occupation of tree cavities by these endothermic animals would result in increased internal air temperatures and reduced relative humidity. This microclimate modification by presence of an active nest should be more pronounced towards the end of the nestling period, when chicks are fully feathered, than during the incubation period. If correct, the internal-ambient temperature differences would be higher, and relative air humidity much lower in active cavities compared to vacant ('unheated') sites, particularly during the nestling period (Maziarz and Wesołowski 2013).

I presumed that the most efficient insulators would be cavities located in the thickest parts of trees, due to lowest heat loss through the thickest cavity walls, and that other cavity characteristics would have a minor influence on cavity insulation (Maziarz et al. 2017). If correct, the differences between daily internal temperature extremes and respective ambient values would change significantly with tree thickness alone. I also expected that well-insulating cavities would retain the greatest amount of heat generated by occupying marsh tits. Consequently, the daily minimum or maximum internalambient temperature differences in active cavities that insulated more efficiently would be greater than corresponding values from vacant cavities with similar insulation.

\section{Materials and methods}

\section{Study area}

The study was conducted during 2013-2014, between midApril and early June, within three permanent study plots in old-growth, oak-lime-hornbeam (Tilio-Carpinetum) stands within Białowieża National Park (BNP, in the strictly protected $47.5 \mathrm{~km}^{2} ; 52^{\circ} 40^{\prime} \mathrm{N}, 23^{\circ} 50^{\prime} \mathrm{E}$ ), E Poland. The climate is subcontinental, with mean annual precipitation of $641 \mathrm{~mm}(426-940 \mathrm{~mm})$ and respective mean temperatures in April and May of $8.0^{\circ} \mathrm{C}$ and $14.5{ }^{\circ} \mathrm{C}$ (Faliński 1986; Wesołowski and Cholewa 2009).

The tree stands are a relic of the primaeval mixed deciduous forests which once covered much of lowland Europe (Tomiałojć and Wesołowski 2004). Tree cavities are diverse and superabundant, giving a wide array of nesting options for cavity users (Walankiewicz 1991; Wesołowski 2007), while nest boxes are absent. Further detailed description of the study site can be found in Tomiałojć et al. (1984) and Wesołowski et al. (2015).

\section{Microclimate measurements}

Measurements of air temperature and relative humidity were taken in two classes of tree cavity: 'active cavities' that contained active marsh tit nests in the observation year $(n=$ $39)$, and 'vacant cavities' $(n=29)$ that had been used by nesting marsh tits in recent breeding seasons, but were 
currently unoccupied when the measurements were taken, due to high abundance of tree cavities providing alternative nest sites (Wesołowski 2007). Vacant cavities contained no nest material, which typically decomposes between breeding seasons (Hebda et al. 2013), or it was manually removed prior to study (after five active nests had failed within the same season). In total, 23 of 29 vacant cavities had been occupied by marsh tits in the same or previous year before the study, and the remainder within 7 years.

All tree cavities studied were formed by natural decay in living trunks, comprising mostly limes (vacant, 24/28 of known tree species; active, 29/39) and hornbeams (respectively $4 / 28$ and 7/39). Median tree girth at breast height was $66 \mathrm{~cm}$ (25-75\% quartiles, $57-73 \mathrm{~cm}, n=28$ ) for vacant cavities and $65 \mathrm{~cm}(25-75 \%, 52-79 \mathrm{~cm} ; n=35)$ for active cavities with measured girth. All tree cavities were $\leq 6 \mathrm{~m}$ above the ground (median $1.5 \mathrm{~m}$ for both cavity classes; $25-75 \%, 1.2-2.5 \mathrm{~m}$, $n=28$ for vacant cavities and $25-75 \%, 1.2-4.0 \mathrm{~m}, n=39$ for active cavities with a measured hole height above the ground), reflecting the location of $66 \%$ of active marsh tit tree cavities in BNP in 2013-2014. The lateral entrance orientation of vacant $(n=28)$ and active $(n=38)$ cavities was randomly distributed, with respective percentages of $32 \%$ and $30 \%$ facing north, $27 \%$ and $22 \%$ east, $14 \%$ and $15 \%$ south and $27 \%$ and $33 \%$ facing west $\left(\chi^{2}=1.9\right.$ and $\left.3.2, \mathrm{df}=3, p>0.4\right)$.

Internal dimensions of all tree cavities were taken using a collapsible ruler and flexible torch (see Wesołowski 1996; Maziarz et al. 2015), after young had fledged from active cavities. Dimensions were similar for vacant and active cavities (Table 1), with vertical distance of the nest below the entrance of $13 \mathrm{~cm}$ (median; $25-75 \%, 10-16 \mathrm{~cm}$ ) in active cavities, and vertical distance from the entrance to the floor of $18 \mathrm{~cm}$ (median; $25-75 \%, 16-21 \mathrm{~cm}$ ) in vacant cavities.

To examine how microclimate varied with nest progression within and between active and vacant cavities, air temperature and humidity were recorded during the incubation and nestling stages, with measurements taken in parallel at both classes of tree cavity. Measurements took place during the incubation stage at a median 7 (range 5-10) days after clutch completion in active cavities, i.e. around the middle of the incubation period when microclimatic conditions should be representative, and during the nestling period when chicks were feathered at a median 12 (range 11-15) days old. Complete sets of measurements were available for $69 \%$ of 39 active and $76 \%$ of 29 vacant cavities, with omissions due to partial or complete nest losses (6 cases), equipment malfunction (4), cavity occupation by other bird species (two vacant cavities) or inclusion of two active cavities found at a later stage of nesting and five tree cavities treated as vacant following nest failures and nest removal (see above). Although the status of some tree cavities changed within or between years, the only cavity to be included in the same category in both seasons was a vacant one at which the measurements were done during the incubation stage in 2013 and chick rearing in 2014.

For all measurements, data loggers (iButtons) measuring temperature (model DS1922L) and temperature and humidity (model DS1923) were used, which were tested and calibrated by Dallas Semiconductor/Maxim Inc. (Maxim Integrated Products $2011 \mathrm{a}, \mathrm{b}$ ). Measurement precision was $\pm 0.5^{\circ} \mathrm{C}$ for temperature and $\pm 5 \%$ for humidity, with an operating range for DS1922L of $-10{ }^{\circ} \mathrm{C}$ to $+65^{\circ} \mathrm{C}$ and for DS1923 from $20^{\circ} \mathrm{C}$ to $+85^{\circ} \mathrm{C}$ and $0 \%$ to $100 \%$ relative humidity.

All measurements were taken simultaneously by paired data loggers positioned inside and outside of each tree cavity to test the buffering of ambient conditions. In active cavities, the internal logger was suspended on a thin wire, typically $7 \mathrm{~cm}$ below the entrance, just above the nest rim and close to the front wall but not touching it, so as not to disturb parental activity. Data loggers inside vacant cavities were typically mounted $7-8 \mathrm{~cm}$ below the entrance hole. The external logger was hung close to the cavity, in cover to minimise
Table 1 The dimensions of vacant and active tree cavities used by marsh tits Poecile palustris in the Białowieża National Park, Poland. For detailed description of assessment of cavity characteristics, see Wesołowski (1996) and Maziarz et al. (2015). Measurements were unavailable for an additional four vacant cavities

\begin{tabular}{|c|c|c|c|c|c|c|}
\hline \multirow[t]{2}{*}{ Cavity characteristics } & \multicolumn{3}{|c|}{ Vacant cavities $(n=25)$} & \multicolumn{3}{|c|}{ Active cavities $(n=39)$} \\
\hline & Median & $25-75 \%$ & Min-max & Median & $25-75 \%$ & Min-max \\
\hline \multicolumn{7}{|l|}{ Entrance } \\
\hline Least diameter $(\mathrm{cm})$ & 2.3 & $2.0-4.0$ & $1.7-6.5$ & 2.5 & $2.0-3.5$ & $1.7-6.5$ \\
\hline Greatest diameter $(\mathrm{cm})$ & 6.5 & $5.0-8.0$ & $3.0-10.0$ & 6.0 & $5.0-7.8$ & $3.0-10.0$ \\
\hline Area $\left(\mathrm{cm}^{2}\right)^{\mathrm{a}}$ & 13.2 & $9.8-16.3$ & $4.9-33.2$ & 13.7 & $9.0-19.0$ & $4.7-38.3$ \\
\hline \multicolumn{7}{|l|}{ Floor } \\
\hline Least diameter $(\mathrm{cm})$ & 7 & $7-9$ & $5-14$ & 8 & $6-9$ & $5-16$ \\
\hline Greatest diameter $(\mathrm{cm})$ & 9 & $8-12$ & $6-15$ & 9 & $8-10$ & $6-18$ \\
\hline Area $\left(\mathrm{cm}^{2}\right)^{\mathrm{a}}$ & 63 & $44-77$ & $24-165$ & 57 & $41-65$ & $24-226$ \\
\hline $\begin{array}{l}\text { Tree girth at hole } \\
\text { height }(\mathrm{cm})\end{array}$ & 67 & $58-79$ & $38-158$ & 60 & $50-74$ & $30-196$ \\
\hline
\end{tabular}

${ }^{\mathrm{a}} 0.5$ least diameter $\times 0.5$ greatest diameter $\times 3.14$ 
direct solar radiation and 2-4 $\mathrm{m}$ above the ground, i.e. aboveground frosts. Both data loggers in a pair were programmed to simultaneously initiate recordings at the expected time of installation and thereafter at 5-min intervals (recording resolution was $0.0625^{\circ} \mathrm{C}$ temperature and $0.04 \%$ humidity). After a minimum $48 \mathrm{~h}$ following installation, the loggers were removed, and the data uploaded to a computer; for further details, see Maziarz and Wesołowski (2013).

\section{Data analysis}

Relative air humidity readings were corrected to the actual temperature and for saturation drift following the manufacturer's equations (Maxim Integrated Products 2011a; p. 53). From each sample, a sequence of records from 00:01 to 24:00 local time was selected to calculate hourly means and to define the mean, minimum and maximum of hourly mean temperature/humidity for a day. The time lag between internal and ambient daily minima or maxima was calculated as the difference in hours between when the respective mean internal and ambient temperature extremes occurred.

To compare thermal conditions between or within vacant and active cavities during the incubation and nestling stages, temperature values inside tree cavities were standardised to ambient conditions using 'temperature differences', subtracting mean, minimum or maximum daily ambient values from the corresponding cavity readings from the same series of measurements. Ambient temperature loggers were previously shown to record values comparable to those obtained from the closest weather station in the Białowieża village (Maziarz et al. 2017), and so their recordings were considered to be representative. Additionally, internal-ambient temperature differences were mostly unaffected by ambient conditions; the mean daily internal-ambient temperature differences remained stable with increasing mean daily ambient temperatures in vacant and active cavities during the two sampling periods corresponding to the incubation and nestling stages in active cavities (Spearman's rank correlation, vacant cavities, $r_{\mathrm{S}}=-0.01$ and -0.23 respectively, $p>0.20$; active cavities, $r_{\mathrm{S}}=-0.32$ and -0.31 respectively, $p>0.05$ ).

To test which cavity characteristics influenced insulation, I performed bootstrapped multiple regression (2000 replications), with minimum or maximum daily internal-ambient temperature differences used as response variables and different cavity characteristics as covariates (all as additive main effects). This method helped to avoid problems of the limited sample sizes and non-normal distributions in the model. In the analyses, I used cavity characteristics that had shown no interdependency, based on results of Spearman's rank correlations. The estimates, standard errors and bias-corrected and accelerated (BCa) confidence intervals of the estimates, were calculated from the sets of bootstrap regression coefficients to assess the statistical importance of the covariates (for a detailed description of the method see Field et al. 2012).

To test if thermal conditions inside tree cavities differed between active and vacant sites depending on their insulation properties, I used bootstrapped ANCOVA models (2000 replications). In these models, daily minimum or maximum internal-ambient temperature differences were set as response variables against covariates of cavity type (active vs. vacant), the cavity characteristic on which the insulation properties of tree cavities depended (a posteriori selection) and the interaction between this characteristic and cavity type. The slopes of change of the internal-ambient temperature differences with the cavity characteristic were assessed and compared statistically between vacant and active cavities based on the estimates, standard errors, and $\mathrm{BCa}$ confidence intervals produced from bootstrapping. This method was used to avoid problems of the limited sample sizes and a non-normal distribution in the models.

For further comparisons of the internal-ambient temperature differences or mean relative humidity between the two cavity types, I used Mann-Whitney tests. The internal-ambient temperature differences between two nesting stages were compared within the same set of tree cavities using Wilcoxon paired tests. Wilcoxon paired tests were used also to test the disparity between internal and ambient humidity measured simultaneously at each tree cavity. The relationships between internal temperatures and the corresponding ambient values were assessed using Spearman's rank correlation.

The statistical calculations followed formulae in $\mathrm{R}$ version 3.4.4 (The R Core Team 2018). For bootstrap analyses, I utilised the boot package in R (Canty and Ripley 2017).

\section{Results}

\section{Daily changes of air temperature in active cavities}

Mean daily air temperatures in active cavities occupied by marsh tits were strongly related to ambient values, both during the incubation (Spearman's rank correlation, $r_{\mathrm{S}}=0.91$, $p<0.001, n=37$ ) and nestling periods (Spearman's rank correlation, $\left.r_{\mathrm{S}}=0.66, p<0.001, n=29\right)$, but the pattern of internal temperature change during the day differed from ambient conditions (Fig. 1).

In the incubation period, temperature extremes in active cavities typically lagged $1-2 \mathrm{~h}$ behind the respective ambient values. Minima averaged $3.5^{\circ} \mathrm{C}$ higher and maxima $1.1^{\circ} \mathrm{C}$ lower compared to outside, whereas mean daily internal temperatures exceeded the ambient values by $1.3^{\circ} \mathrm{C}$ on average (Fig. 1; Table 2). In the nestling period, mean hourly internal temperatures were consistently higher than outside (Fig. 1), with daily means, minima and maxima surpassing the ambient values by respective averages of $3.9,5.0$ and $2.6{ }^{\circ} \mathrm{C}$ (Table 2). 
Fig. 1 Daily changes in the mean hourly air temperature (a $n=37$ and $\mathbf{b} n=29)$ and relative humidity (c $n=24$ and $\mathbf{d} n=14$ ) in active tree cavities (black dots) used by nesting marsh tits Poecile palustris in relation to ambient conditions (white dots) in the incubation and nestling periods in 2013-2014. Shown are means (dots) and standard errors (whiskers) a

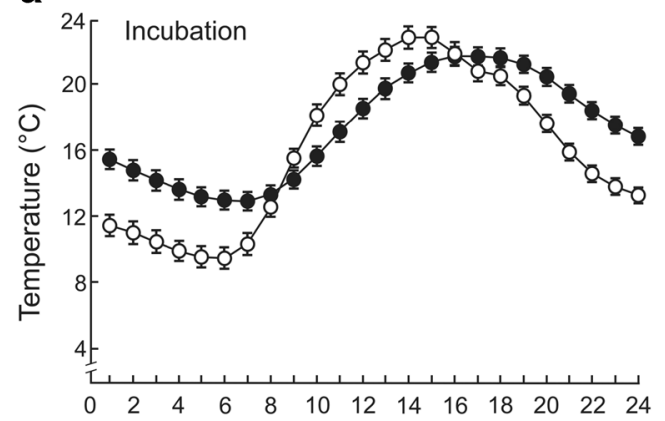

b

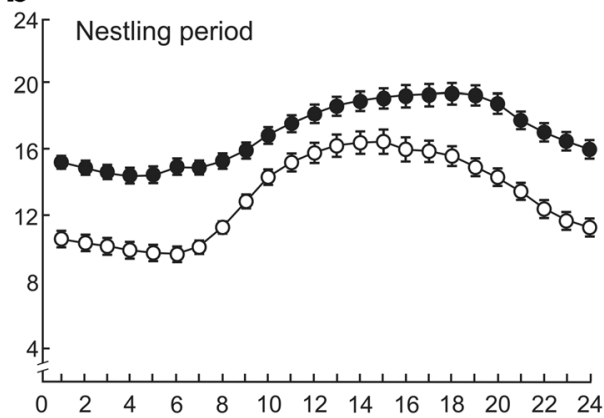

C

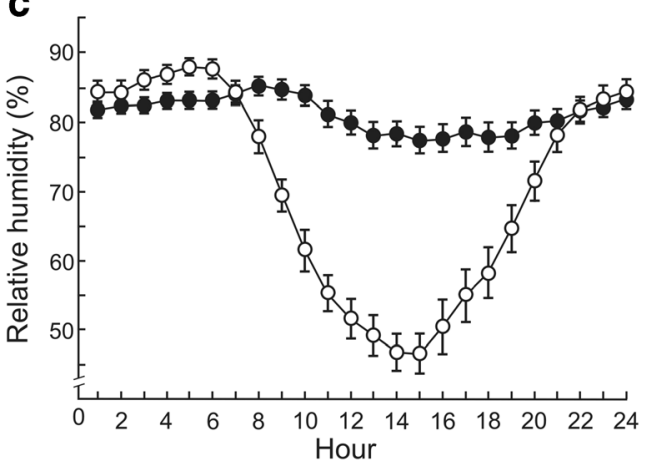

d

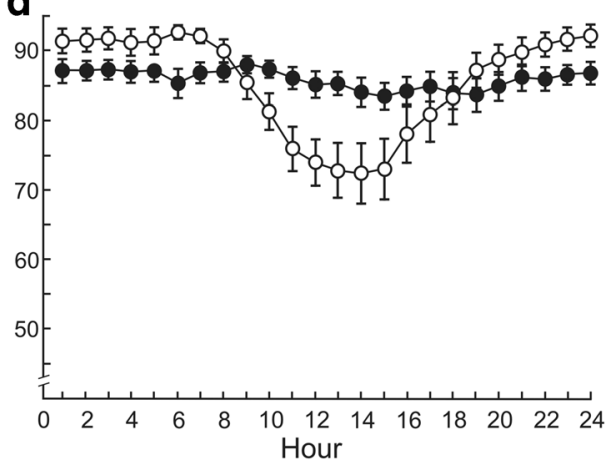

At this stage, internal extremes typically lagged $2-3 \mathrm{~h}$ behind ambient values (Fig. 1).

Table 2 Mean, minimum and maximum daily ambient temperatures and respective internal-ambient temperature differences $\left({ }^{\circ} \mathrm{C}\right)$ in the incubation and nestling periods in vacant and active tree cavities used by nesting marsh tits. The values shown refer to hourly means

\begin{tabular}{|c|c|c|c|c|c|c|}
\hline \multirow[t]{2}{*}{ Nesting stage } & \multicolumn{2}{|c|}{ Vacant cavities } & \multicolumn{2}{|c|}{ Active cavities } & \multicolumn{2}{|c|}{ Mann-Whitney test } \\
\hline & Mean & SD & Mean & $\mathrm{SD}$ & $W$ & $p$ \\
\hline Incubation & \multicolumn{2}{|c|}{$n=24$ cavities } & \multicolumn{2}{|c|}{$n=37$ cavities } & & \\
\hline \multicolumn{7}{|c|}{ Ambient temperatures } \\
\hline Mean & 15.0 & 2.93 & 16.1 & 3.05 & 535 & 0.181 \\
\hline Minimum & 8.4 & 3.89 & 9.3 & 3.64 & 523 & 0.249 \\
\hline Maximum & 21.7 & 3.78 & 23.4 & 3.47 & 572 & 0.060 \\
\hline \multicolumn{7}{|c|}{ Internal-ambient temperature differences } \\
\hline Mean & -0.2 & 0.61 & 1.3 & 1.11 & 819 & $<0.001$ \\
\hline Minimum & 2.0 & 1.17 & 3.5 & 1.26 & 731 & $<0.001$ \\
\hline Maximum & -2.5 & 2.07 & -1.1 & 2.09 & 620 & 0.010 \\
\hline Nestling period & \multicolumn{2}{|c|}{$n=27$ cavities } & \multicolumn{2}{|c|}{$n=29$ cavities } & & \\
\hline \multicolumn{7}{|c|}{ Ambient temperatures } \\
\hline Mean & 14.4 & 2.79 & 13.2 & 2.23 & 287 & 0.088 \\
\hline Minimum & 10.2 & 3.67 & 8.8 & 2.50 & 297 & 0.123 \\
\hline Maximum & 18.9 & 3.15 & 17.5 & 3.27 & 297 & 0.121 \\
\hline \multicolumn{7}{|c|}{ Internal-ambient temperature differences } \\
\hline Mean & -0.2 & 0.88 & 3.9 & 2.07 & 769 & $<0.001$ \\
\hline Minimum & 1.2 & 0.71 & 5.0 & 1.93 & 765 & $<0.001$ \\
\hline Maximum & -2.0 & 1.78 & 2.6 & 2.80 & 718 & $<0.001$ \\
\hline
\end{tabular}

\section{Thermal conditions in active cavities in comparison to vacant sites}

At comparable ambient temperatures, daily internal-ambient temperature differences were significantly higher in active than in vacant cavities, with most pronounced disparities in the nestling period (Table 2). This was due to an increase of internal temperatures relative to outside between the two nesting stages in active cavities (Wilcoxon paired test for daily means, $V=1, p<0.001, n=27$ ), as in vacant sites, the values remained unchanged between both periods (Wilcoxon paired test, $V=129, p=0.664, n=22$ ).

The ambient temperature extremes were reduced to the greatest extent in vacant cavities situated in the thickest parts of trees, with other cavity parameters having a minor influence on the buffering capacity of these cavities (95\% confidence intervals overlapping with zero; Table 3 ).

Although internal daily minimum temperatures in vacant cavities increased relative to outside with the increasing tree thickness (Table 3), the difference between internal and ambient daily minima remained stable in active cavities (Fig. 2, Table 4). Consequently, the disparities between the two types of cavities were greatest for those located in the thinnest trees (Fig. 2), although the interaction between tree girth and cavity type was significant only in the incubation period (Table 4).

As in vacant cavities, the differences between internal and ambient daily maximum temperatures were lowest in active cavities placed in thickest trees, with a consistent pattern during the two nesting stages (Fig. 2; Table 4). 
Table 3 Results of bootstrapped (2000 replications) multiple regression showing changes in minimum or maximum daily internal-ambient temperature differences with dimensions and location in a tree of vacant cavities ( $n=22$ cavities at each stage) in the periods corresponding to the incubation and chick rearing at active cavities. Vacant cavities were previously used by nesting marsh tits but remained empty during the study. Cavity parameters showed no interdependency. Only cavities with a full set of available measurements were included

\begin{tabular}{|c|c|c|c|c|c|c|c|c|}
\hline \multirow[t]{2}{*}{ Variable } & \multicolumn{4}{|c|}{ Incubation } & \multicolumn{4}{|c|}{ Nestling period } \\
\hline & Estimate & SE & $95 \% \mathrm{CI}^{\mathrm{a}}$ & & Estimate & SE & $95 \% \mathrm{CI}^{\mathrm{a}}$ & \\
\hline \multicolumn{9}{|c|}{ Minimum daily internal-ambient differences } \\
\hline Intercept & -0.61 & 1.20 & -2.61 & 2.39 & -0.58 & 0.69 & -1.77 & 1.03 \\
\hline Tree girth ${ }^{\mathrm{b}}$ & 0.04 & 0.01 & 0.02 & 0.06 & 0.01 & 0.01 & 0.00 & 0.03 \\
\hline Entrance $\operatorname{area}^{\mathrm{c}}$ & -0.03 & 0.03 & -0.08 & 0.01 & 0.00 & 0.23 & -0.03 & 0.06 \\
\hline Floor $\operatorname{area}^{\mathrm{c}}$ & -0.01 & 0.01 & -0.03 & 0.01 & 0.00 & 0.01 & -0.01 & 0.01 \\
\hline Hole depth ${ }^{\mathrm{d}}$ & 0.05 & 0.04 & -0.01 & 0.16 & 0.03 & 0.03 & -0.02 & 0.12 \\
\hline Hole height $\mathrm{e}^{\mathrm{e}}$ & 0.01 & 0.18 & -0.42 & 0.23 & 0.12 & 0.13 & -0.11 & 0.35 \\
\hline \multicolumn{9}{|c|}{ Maximum daily internal-ambient differences } \\
\hline Intercept & 2.68 & 2.36 & -1.36 & 7.35 & 0.04 & 2.43 & -3.41 & 7.01 \\
\hline Tree girth ${ }^{\mathrm{b}}$ & -0.07 & 0.02 & -0.11 & -0.03 & -0.04 & 0.03 & -0.07 & 0.04 \\
\hline Entrance $\operatorname{area}^{\mathrm{c}}$ & 0.00 & 0.05 & -0.14 & 0.06 & -0.02 & 0.07 & -0.13 & 0.12 \\
\hline Floor area ${ }^{\mathrm{c}}$ & 0.03 & 0.02 & -0.01 & 0.07 & 0.00 & 0.02 & -0.05 & 0.04 \\
\hline Hole depth ${ }^{\mathrm{d}}$ & -0.07 & 0.07 & -0.21 & 0.04 & -0.03 & 0.08 & -0.21 & 0.11 \\
\hline Hole height ${ }^{\mathrm{e}}$ & -0.25 & 0.39 & -0.99 & 0.65 & 0.65 & 0.53 & -0.20 & 1.87 \\
\hline
\end{tabular}

${ }^{\mathrm{a}}$ Lower and upper bias-corrected and accelerated (BCa) bootstrap confidence intervals

${ }^{\mathrm{b}}$ Measured at hole height $(\mathrm{cm})$

${ }^{\mathrm{c}} 0.5$ least diameter $\times 0.5$ greatest diameter $\times 3.14\left(\mathrm{~cm}^{2}\right)$

${ }^{\mathrm{d}}$ Vertical floor distance to the lower edge of the entrance $(\mathrm{cm})$

${ }^{\mathrm{e}}$ Height above the ground (m)

\section{Relative air humidity in active and vacant cavities}

Mean hourly relative humidity was stable in active cavities during the 24-h period, despite fluctuating ambient conditions (Fig. 1), and averaged just above $80 \%$, equalling or exceeding the corresponding ambient values in both nesting stages (Table 5). Under comparable ambient conditions at active (Table 5) and vacant cavities (mean daily ambient humidity averaging between $75.9 \%$ and $87.5 \%, \mathrm{SD}=8.3$ and 6.6 respectively), the internal humidity was much lower in active (Table 5) than in vacant sites, where it amounted to $91.4 \%$ (mean, $\mathrm{SD}=3.1$ ) in the period corresponding to the incubation and $94.3 \%$ (mean, $\mathrm{SD}=2.7$ ) in the nestling stage (MannWhitney tests, comparison between internal values at active and vacant cavities in the respective nesting stages: $W=22$ and $14, p<0.001)$.

\section{Discussion}

\section{Modification of the initial cavity microclimate by the occupants}

The study shows that marsh tits visibly modified the initial microclimate of tree cavities they used for nesting. The presence of active nests inside these occupied cavities resulted in an elevated internal air temperature and lower relative air humidity, compared to vacant sites, with the greatest contrasts recorded in the late nestling period. As relative humidity depends on both the amount of water vapour in the air and the air temperature, the lower relative humidity was likely due to changes in heat production by the birds. Despite this microclimate modification, the patterns of daily temperature and humidity change in occupied nest sites remained similar to vacant cavities (Maziarz et al. 2017); daily air temperature amplitudes in active cavities still ranged within the corresponding ambient values, internal temperature extremes lagged the ambient ones, and relative humidity was stable at fluctuating ambient values.

The results confirm previous findings showing a quantifiable impact of endothermic activity of animals on cavity microclimate (e.g. Kendeigh 1961; Havera 1979; du Plessis et al. 1994; Willis and Brigham 2007; Vel'ký et al. 2010; Griffiths et al. 2017). The temperature increase with nest progression, recorded in active cavities of marsh tits, was consistent with observations in nest cavities of the Syrian woodpecker Dendrocopos syriacus (Mersten-Katz et al. 2012) and the great tit Parus major (Maziarz and Wesołowski 2013). However, a similar change of internal temperatures relative to outside was subtle in nest cavities of the Carolina chickadee Poecile carolinensis (Albano 1992) and was absent in those of the northern flicker Colaptes auratus (Howe et al. 1987).

The modification of thermal conditions inside tree cavities occupied by breeding marsh tits was comparable to a previous study of tree cavities used by breeding great tits in the same 
Fig. 2 Minimum $(\mathbf{a}, \mathbf{b})$ and maximum (c, d) daily internalambient temperature differences in vacant (white dots) and active (black dots) tree cavities used by nesting marsh tits in relation to tree girth at hole height in the incubation and nestling periods. Shown are trend lines and 95\% confidence intervals
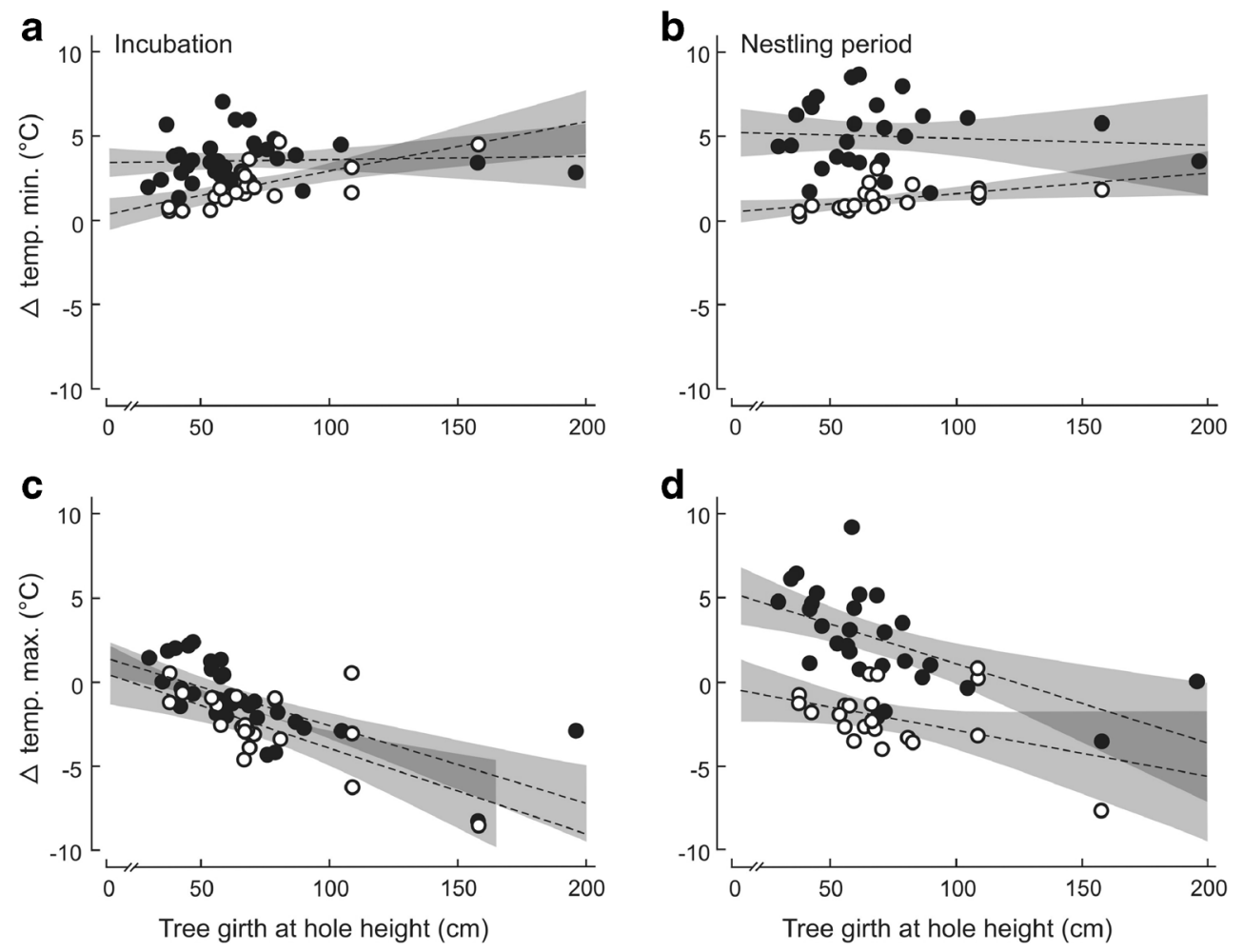

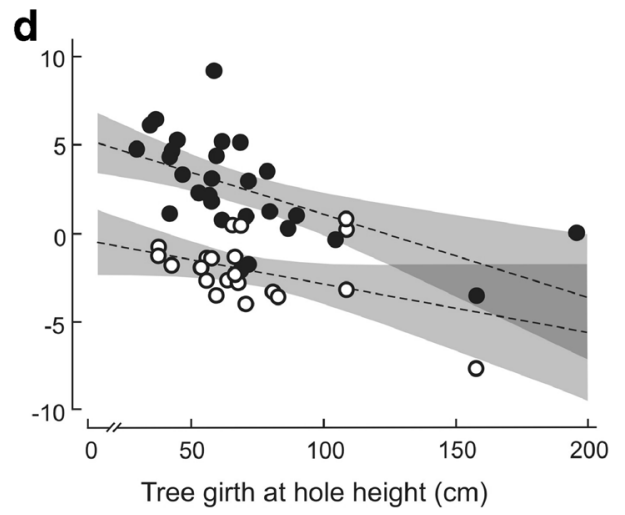

d

Tree girth at hole height $(\mathrm{cm})$ forest within BNP. The divergence of mean daily internalambient temperature differences between active and vacant cavities used by marsh tits averaged only $0.4-0.6^{\circ} \mathrm{C}$ higher than between active and vacant cavities used by great tits (Maziarz and Wesołowski 2013). This small difference was notable because great tits in BNP typically occupied tree cavities that reduced ambient temperature extremes more effectively than marsh tits (Maziarz and Wesołowski 2013; Maziarz et al. 2017), and laid larger clutches of a median 10 eggs compared to the 7 eggs of marsh tits (Wesołowski 2003;
Maziarz et al. 2016). Incubation of larger clutches may require greater energy expenditure by female birds (Biebach 1981; Haftorn and Reinertsen 1985), and larger broods of young would also be expected to generate proportionately more heat in the nest. As such, the amount of heat produced and retained inside nest cavities of great tits would be expected to be much higher than those of marsh tits. The raising of the internal temperatures, relative to outside, by a similar degree in both tit species might indicate that birds compensated for varying initial microclimates by appropriately modifying their heat
Table 4 Results of bootstrapped (2000 replications) ANCOVA comparing changes in minimum and maximum daily internalambient temperature differences with tree girth at hole height in active ( $n=37$ and 29 respectively) and vacant cavities $(n=22$ at each stage) in the incubation and nestling periods. Only cavities with a full set of available measurements were included

\begin{tabular}{|c|c|c|c|c|c|c|c|c|}
\hline \multirow[t]{2}{*}{ Variable } & \multicolumn{4}{|c|}{ Incubation } & \multicolumn{4}{|c|}{ Nestling period } \\
\hline & Estimate & SE & \multicolumn{2}{|l|}{$95 \% \mathrm{CI}^{\mathrm{a}}$} & Estimate & SE & \multicolumn{2}{|l|}{$95 \% \mathrm{CI}^{\mathrm{a}}$} \\
\hline \multicolumn{9}{|c|}{ Minimum daily internal-ambient differences } \\
\hline Intercept ${ }^{\mathrm{b}}$ & 3.37 & 0.62 & 2.14 & 4.43 & 5.28 & 0.82 & 3.64 & 6.79 \\
\hline Tree girth $^{\mathrm{b}}$ & 0.00 & 0.01 & -0.01 & 0.02 & 0.00 & 0.01 & -0.02 & 0.02 \\
\hline Cavity type ${ }^{\mathrm{c}}$ & -3.48 & 0.83 & -5.18 & -1.85 & -4.91 & 0.90 & -6.51 & -3.06 \\
\hline Tree girth $\times$ cavity type & 0.03 & 0.01 & 0.00 & 0.05 & 0.02 & 0.01 & -0.01 & 0.03 \\
\hline \multicolumn{9}{|c|}{ Maximum daily internal-ambient differences } \\
\hline Intercept $^{\mathrm{b}}$ & 2.02 & 1.18 & 0.13 & 4.13 & 5.83 & 1.24 & 3.53 & 8.02 \\
\hline Tree girth ${ }^{\mathrm{b}}$ & -0.05 & 0.02 & -0.08 & -0.02 & -0.05 & 0.02 & -0.08 & -0.02 \\
\hline Cavity type $^{\mathrm{c}}$ & -0.87 & 1.76 & -3.92 & 2.22 & -5.93 & 1.99 & -9.22 & -2.03 \\
\hline Tree girth $\times$ cavity type & 0.00 & 0.03 & -0.05 & 0.05 & 0.02 & 0.03 & -0.03 & 0.07 \\
\hline
\end{tabular}

${ }^{\mathrm{a}}$ Lower and upper bias-corrected and accelerated (BCa) bootstrap confidence intervals

${ }^{\mathrm{b}}$ For active cavities

${ }^{\mathrm{c}}$ For vacant cavities in comparison to active ones 
Table 5 Mean, minimum and maximum daily internal and ambient relative air humidity (\%) in active tree cavities of marsh tits in the incubation and nestling periods. The values shown refer to hourly means

\begin{tabular}{|c|c|c|c|c|c|c|}
\hline \multirow[t]{2}{*}{ Nesting stage } & \multicolumn{2}{|l|}{ Internal } & \multicolumn{2}{|l|}{ Ambient } & \multicolumn{2}{|c|}{ Wilcoxon paired test } \\
\hline & Mean (SD) & Range & Mean (SD) & Range & V & $p$ \\
\hline Incubation period & $n=24$ cavities & & & & & \\
\hline Mean & $81.4(6.9)$ & $60-89$ & $70.4(10.5)$ & $55-88$ & 296 & $<0.001$ \\
\hline Minimum & $73.8(9.0)$ & $47-86$ & $44.4(14.2)$ & $25-74$ & 300 & $<0.001$ \\
\hline Maximum & $88.0(4.5)$ & $75-94$ & $90.3(5.2)$ & $79-97$ & 40 & 0.001 \\
\hline Nestling period & $n=14$ cavities & & & & & \\
\hline Mean & $85.9(5.7)$ & $77-94$ & $85.4(6.0)$ & $76-94$ & 60 & 0.670 \\
\hline Minimum & $78.5(8.6)$ & $64-91$ & $65.8(13.7)$ & $46-92$ & 96 & 0.004 \\
\hline Maximum & $91.3(4.0)$ & $84-97$ & $95.9(1.2)$ & $95-98$ & 9 & 0.004 \\
\hline
\end{tabular}

generation within nest cavities to meet similar thermal requirements (Webb 1987).

\section{Modification of cavity microclimate in relation to cavity insulation}

As in other studies (e.g. Wiebe 2001; Paclík and Weidinger 2007; Isaac et al. 2008; Coombs et al. 2010; Maziarz et al. 2017; Vierling et al. 2018), those vacant cavities situated in the thickest parts of trees buffered most efficiently from ambient temperature extremes. Other cavity characteristics, such as hole height above the ground, entrance size, cavity depth or floor area, were less important in moderating the extremes. This showed that the thermal conditions of tree cavities used by marsh tits seemed to depend mostly on heat transfer through cavity walls, which were thicker in larger trees (Maziarz et al. 2017). As all cavities studied were situated in living trees, the water transported in the tree tissues probably further reduced the heat transfer through the cavity walls (e.g. Wiebe 2001; Coombs et al. 2010).

Nevertheless, the heating effect of marsh tit breeding activity was most pronounced in cavities placed in the thinnest parts of trees, which insulated least effectively, and where the disparity between minimum daily internal-ambient temperature differences for active and vacant sites was greatest. As minimum daily internal-ambient temperature differences remained stable in all active cavities, marsh tits seemed to compensate for the increased rate of heat loss through the walls of cavities in thinner trees by generating proportionately more heat within them (Mertens 1980).

These findings were in stark contrast to the expectations of greater heat retention in tree cavities that insulate most efficiently. Such expectations were based on observations from nest boxes, where those with improved insulation resulted in a greater internal temperature increase in response to an artificial heat source within, compared to those nest boxes without additional insulation (Kearney et al. 2011; Larson et al. 2018). Following installation of heat pads, Grüebler et al. (2014) recorded only a slightly greater temperature increase in empty tree cavities compared to nest boxes, which insulated less effectively. Nonetheless, the results of the current study confirm the patterns recorded by Vel'ký et al. (2010) in vacant and occupied nest boxes used by roosting great tits, where the increase of internal-ambient temperature differences due to presence of a bird tended to be greater when boxes lacked additional insulation, compared to when insulation was provided. Thus, unlike artificial heat sources, marsh tits seemed to actively modify thermal conditions inside their cavities by raising daily minimum air temperatures in a homeostatic manner, with respect to cavity insulation and ambient conditions (see also Ricklefs and Hainsworth 1969). Warming up the air and raising the minimum internal-ambient temperature differences to the same level in all active tree cavities was likely a by-product of the endothermic activity of nesting birds, necessary to meet the minimum thermal demands. Expending the additional amount of heat in nest cavities that insulated less efficiently could be essential to maintain the required egg temperature of c. $36-38^{\circ} \mathrm{C}$ (Webb 1987) for normal development of embryos (e.g. Haftorn and Reinertsen 1985), or for selfmaintenance to avoid hypothermia (O'Connor 1975; Mertens 1977a).

As the maximum daily internal-ambient temperature differences decreased with increasing tree girth at hole height in vacant and active cavities, daily ambient maxima were consistently moderated in cavities located in the thickest trees (Maziarz et al. 2017). These buffering properties of tree cavities could be particularly important for cavity-nesting birds on hot days, when ambient temperatures exceed $30^{\circ} \mathrm{C}$ and large broods of fully feathered chicks in the smallest cavities may be at risk of hyperthermia (e.g. Mertens 1977b; van Balen 1984). Yet, these properties of tree cavities could also be crucial for other endothermic animals that use cavities for breeding or roosting, such as many mammals, especially in hot environments, where protection against extreme temperatures is pivotal (e.g. O'Connell and Keppel 2016; Rowland et al. 2017; Griffiths et al. 2018).

Using poorly buffering tree cavities might be costly for birds or other endothermic animals, due to greater energy 
expenditures or increased risk of overheating. However, the potential costs that the occupants might incur in such tree cavities would likely be lower than in standard wooden nest boxes, which are commonly provided as substitutes for tree cavities but are usually ineffective in moderating ambient temperature extremes (e.g. McComb and Noble 1981; AmatValero et al. 2014; Griffiths et al. 2017, 2018; Maziarz et al. 2017; Rowland et al. 2017). For example, to the best of my knowledge, all cases of chick mortality due to overheating were reported only from nest boxes (e.g. Mertens 1977b; van Balen 1984), with no similar incidences found in tree cavities. Thus, the metabolic rates of animals, or mortality risks due to overheating, would be expected to differ for those using nest boxes compared to those occupying tree cavities, with presumably the greatest disparities present at extreme temperatures (Rowland et al. 2017). As such, comparative observations of animals occupying both types of sites would be valuable to fully understand the threats and energetics of cavity users.

\section{The role of cavity microclimate in nest site selection}

Occupying well-insulating and moderately humid tree cavities could be advantageous for breeding birds (see "Introduction"), but marsh tits rarely use such sites, even with the availability of a large diversity of nesting options (Walankiewicz 1991; reviewed in Wesołowski 2007). Instead, marsh tits typically occupy cavities located in thin, living trees, where fluctuations in daily air temperature are relatively large and relative humidity often exceeds $90 \%$ prior to nest building by the birds (Wesołowski 1996; Maziarz et al. 2017). As shown in the current study, the breeding activity of birds reduced internal humidity by about $10 \%$ on average, but the values stayed at a level where hindered evaporation and ventilation could be still problematic by reducing the hatching success of chicks (Walsberg and Schmidt 1992).

As the nest site choice of marsh tits is unlikely to be limited by the availability of suitable tree cavities in BNP (Wesołowski 1996, 2007), the occupation of nest sites with advantageous microclimates seems to be constrained by other priorities. Avoidance of nest predation, which is the main cause of nest loss and mortality of breeding adults in BNP (reviewed in Wesołowski and Tomiałojć 2005), could be the main reason of the microclimate trade-off. By using cavities in thinner trees, which are more abundant in this forest than thicker stems (Wesołowski 1996; Maziarz and Broughton 2015), marsh tits nesting at low densities might greatly reduce the risk of detection by predators (Wesołowski 2002). To find marsh tit nests, predators would have to inspect numerous potential nest sites, and this would limit their hunting efficiency. Reducing the predation risk by occupying only a small fraction of available nest sites can be a common antipredator behaviour of birds (e.g. Martin 1993), and so this may also operate in marsh tits (Wesołowski 2002).

Additionally, strong walls of living wood around tree cavities could deter larger predators, such as the great spotted woodpecker Denrocopos major or pine marten Martes martes, which are less likely to breach them and access the nests (Walankiewicz 1991; Wesołowski 2002 and references therein; Czeszczewik and Walankiewicz 2003; Maziarz et al. 2016). As such, marsh tits, like other songbirds (e.g. reviewed in Collias and Collias 1984; de Zwaan and Martin 2018), probably balance their microclimatic requirements with nest safety when selecting their nest sites. The costs incurred when using tree cavities with sub-optimal microclimates could be mitigated by birds to some extent, however, for example, by building nests composed of well-insulating materials or laying smaller clutches of eggs and so raising smaller broods in less spacious cavities, all of which might reduce energy expenditure and the risk of overheating (e.g. Biebach 1981; O’Connor 1975; Mertens 1977b; Walsberg and King 1978; van Balen 1984; Lombardo et al. 1995; de Zwaan and Martin 2018).

\section{Conclusions}

The study provides new information on the effects of birds' breeding activity on the microclimate of tree cavities used for nesting. As hypothesised, the presence of an active marsh tit nest within a cavity resulted in elevation of the initial internal temperature and a reduction of the relative humidity. This microclimate modification was more pronounced during the nestling period than in the incubation stage, being associated with increased heating activity by the birds as the nesting progressed.

Birds appeared to modify their heat production in a homeostatic manner, by warming the air to a greater extent within cavities that insulated less efficiently, and raising the minimum daily temperatures compared to ambient minima to a similar level in all nest sites. Additionally, as maximum daily internal temperatures were tempered most in tree cavities situated in the thickest trees, the buffering properties of tree cavities seemed to play an important role in reducing the risk of overheating.

Despite the apparent advantages of occupying wellinsulating tree cavities with a moderate humidity, marsh tits rarely use holes with apparently optimal microclimates, probably due to avoidance of other threats, such as nest predation. The ability of birds to compensate for the potential costs associated with less suitable thermal and humidity conditions inside tree cavities may be essential for accommodating opposing selective forces and to breed in a wide range of ambient weather conditions. 
Acknowledgements I am grateful to M. Cholewa, M. Czuchra, G. Hebda, P. Rowiński and T. Wesołowski for their support in fieldwork, including nest checks and microclimate measurements. I thank the two anonymous reviewers for their useful comments, and the kind cooperation of the Białowieża National Park administration was also highly appreciated. The study was supported by an internal grant from the Faculty of Biological Sciences, Wrocław University.

\section{Compliance with ethical standards}

The research complied with current Polish law. The article does not contain any studies with human participants or animals performed by the author.

Open Access This article is distributed under the terms of the Creative Commons Attribution 4.0 International License (http:// creativecommons.org/licenses/by/4.0/), which permits unrestricted use, distribution, and reproduction in any medium, provided you give appropriate credit to the original author(s) and the source, provide a link to the Creative Commons license, and indicate if changes were made.

\section{References}

Albano DJ (1992) Nesting mortality of Carolina chickadees breeding in natural cavities. Condor 94:371-382

Amat-Valero M, Calero-Torralbo MA, Václav R, Valera F (2014) Cavity types and microclimate: implications for ecological, evolutionary, and conservation studies. Int J Biometeorol 58:1983-1994

van Balen JH (1984) The relationship between nest-box size, occupation and breeding parameters of the great tit Parus major and some other hole-nesting species. Ardea 72:163-175

Biebach H (1981) Energetic costs of incubation on different clutch sizes in starlings (Sturnus vulgaris). Ardea 69:141-142

Broughton RK, Hill RA, Bellamy PE, Hinsley SA (2011) Nest-sites, breeding failure, and causes of non-breeding in a population of British marsh tits Poecile palustris. Bird Study 58:229-237

Canty A, Ripley BD (2017) Boot: bootstrap R (S-plus) functions. R package version 1.3-20

Collias NE, Collias EC (1984) Nest building and bird behaviour. Princeton University Press, Princeton, New Jersey

Coombs AB, Bowman J, Garroway CJ (2010) Thermal properties of tree cavities during winter in a northern hardwood forest. J Wildl Manag $74: 1875-1881$

Cramp S, Perrins CM (eds) (1993) The birds of the Western Palearctic, vol VII: flycatchers to shrikes. Oxford University Press, Oxford

Czeszczewik D, Walankiewicz W (2003) Natural nest sites of the pied flycatcher Ficedula hypoleuca in a primeval forest. Ardea 91:221230

Deeming DC (2011) Importance of nest type on the regulation of humidity in bird nests. Avian Biol Res 4:23-31

Faliński JB (1986) Vegetation dynamics in temperate forests. Ecological studies in Białowieża forest. Dr W Junk, Dordrecht

Field A, Miles J, Field Z (2012) Discovering statistics using R. SAGE, London

Gibbons P, Lindenmayer D (2002) Tree hollows and wildlife conservation in Australia. CSIRO Publishing, Collingwood

Griffiths SR, Rowland JA, Briscoe NJ, Lentini PE, Handasyde KA, Lumsden LF, Robert KA (2017) Surface reflectance drives nest box temperature profiles and thermal suitability for target wildlife. PLoS One 12(5):e0176951

Griffiths SR, Lentini PE, Semmens K, Watson SJ, Lumsden LF, Robert KA (2018) Chainsaw-carved cavities better mimic the thermal properties of natural tree hollows than nest boxes and log hollows. Forests 9:235. https://doi.org/10.3390/19050235

Grüebler MU, Widmer S, Korner-Nievergelt F, Naef-Daenzer B (2014) Temperature characteristics of winter roost-sites for birds and mammals: tree cavities and anthropogenic alternatives. Int J Biometeorol 58:629-637

Haftorn S, Reinertsen RE (1985) The effect of temperature and clutch size on the energetic cost of incubation in a free-living blue tit (Parus caeruleus). Auk 102:470-478

Havera SP (1979) Temperature variation in a fox squirrel nest box. J Wildl Manag 43:251-253

Hebda G, Pochrząst K, Mitrus S, Wesołowski T (2013) Disappearance rates of old nest material from tree cavities: an experimental study. Scand J For Res 28:445-450

Howe S, Kilgore DL, Colby C (1987) Respiratory gas concentrations and temperatures within nest cavities of the northern flicker (Colaptes auratus). Can J Zool 65:1541-1547

Isaac JL, De Gabriel JL, Goodman BA (2008) Microclimate of daytime den sites in a tropical possum: implications for the conservation of tropical arboreal marsupials. Anim Conserv 11:281-287

Kearney M, Ferguson E, Fumei S, Gallacher A, Mitchell P, Woodford R, Handasyde K (2011) A cost-effective method of assessing thermal habitat quality for endotherms. Austral Ecol 36:297-302

Kendeigh SC (1961) Energy of birds conserved by roosting in cavities. Wilson Bull 73:140-147

Larson ER, Eastwood JR, Buchanan KL, Bennett ATD, Berg ML (2018) Nest box design for a changing climate: the value of improved insulation. Ecol Manag Restor 19:39-48

Lombardo MP, Bosman RM, Faro CA, Houtteman SG, Kluisza TS (1995) Effect of feathers as nest insulation on incubation behavior and reproductive performance of tree swallows (Tachycineta bicolor). Auk 112:973-981

Martin TE (1993) Nest predation and nest sites. New perspectives on old patterns. BioScience 43:523-532

Maxim Integrated Products, Inc (2011a) DS1923: Hygrochron Temperature/Humidity Logger iButton with 8KB Data-Log Memory 19-4991, Rev 4

Maxim Integrated Products, Inc (2011b) DS1922L/ DS1922T: Temperature Logger iButton with 8KB Data-Log Memory 194990, Rev 10

Maziarz M, Broughton RK (2015) Breeding microhabitat selection by great tits Parus major in a deciduous primeval forest (Białowieża National Park, Poland). Bird Study 62:358-367

Maziarz M, Wesołowski T (2013) Microclimate of tree cavities used by great tits (Parus major) in a primeval forest. Avian Biol Res 6:47-56

Maziarz M, Wesołowski T, Hebda G, Cholewa M (2015) Natural nestsites of great tits (Parus major) in a primeval temperate forest (Białowieża National Park, Poland). J Ornithol 156:613-623

Maziarz M, Wesołowski T, Hebda G, Cholewa M, Broughton RK (2016) Breeding success of the great tit Parus major in relation to attributes of natural nest cavities in a primeval forest. J Ornithol 157:343-354

Maziarz M, Broughton RK, Wesołowski T (2017) Microclimate in tree cavities and nest-boxes: implications for hole-nesting birds. For Ecol Manag 389:306-313

McComb WC, Noble RE (1981) Microclimates of nest boxes and natural cavities in bottomland hardwoods. J Wildl Manag 45:284-289

Mersten-Katz C, Barnea A, Yom-Tov Y, Ar A (2012) The woodpecker's cavity microenvironment: advantageous or restricting? Avian Biol Res 5:227-237

Mertens JAL (1977a) Thermal conditions for successful breeding in great tits (Parus major L.). I. Relation of growth and development of temperature regulation in nestling great tits. Oecologia 28:1-29

Mertens JAL (1977b) Thermal conditions for successful breeding in great tits (Parus major L.). II. Thermal properties of nests and nestboxes and their implications for the range of temperature tolerance of great tit broods. Oecologia 28:31-56 
Mertens JAL (1980) The energy requirements for incubation in great tits and other bird species. Ardea 68:185-192

O'Connell C, Keppel G (2016) Deep tree hollows: important refuges from extreme temperatures. Wildl Biol 22:305-310

O'Connor RJ (1975) The influence of brood size upon metabolic rate and body temperature in nestling blue tits Parus caeruleus and house sparrows Passer domesticus. J Zool 175:391-403

Paclík M, Weidinger K (2007) Microclimate of tree-cavities during winter nights - implications for roost site selection in birds. Int J Biometeorol 51:287-293

du Plessis MA, Weathers WW, Koenig WD (1994) Energetic benefits of communal roosting by acorn woodpeckers during the nonbreeding season. Condor 96:631-637

R Core Team (2018) R: a language and environment for statistical computing. R Foundation for Statistical Computing. URL https://www. R-project.org/. Accessed 15. 10. 2018

Ricklefs RE, Hainsworth FR (1969) Temperature regulation in nestling cactus wrens: the nest environment. Condor 71:32-37

Rowland JA, Briscoe NJ, Handasyde KA (2017) Comparing the thermal suitability of nest-boxes and tree-hollows for the conservationmanagement of arboreal marsupials. Biol Conserv 209:341-348

Salaberria C, Celis P, López-Rull I, Gil D (2014) Effects of temperature and nest heat exposure on nestling growth, dehydration and survival in a Mediterranean hole-nesting passerine. Ibis 156:265-275

Tomiałojć L, Wesołowski T (2004) Diversity of the Białowieża Forest avifauna in space and time. J Ornithol 145:81-92

Tomiałojć L, Wesołowski T, Walankiewicz W (1984) Breeding bird community of a primaeval temperate forest (Białowieża National Park, Poland). Acta Ornithol 20:241-310

Vel'ký M, Kaňuch P, Krištín A (2010) Selection of winter roosts in the great tit Parus major: influence of microclimate. J Ornithol 151: $147-153$

Vierling KT, Lorenz TJ, Cunningham P, Potterf K (2018) Thermal conditions within tree cavities in ponderosa pine (Pinus ponderosa) forests: potential implications for cavity users. Int $\mathrm{J}$ Biometeorol 62:553-564
Walankiewicz W (1991) Do secondary cavity nesting birds suffer more from competition for cavities or from predation in a primeval deciduous forest? Nat Areas J 11:203-211

Walsberg GE, King JR (1978) The energetic consequences of incubation for two passerine species. Auk 95:644-655

Walsberg GE, Schmidt CA (1992) Effects of variable humidity on embryonic development and hatching success of mourning doves. Auk 109:309-314

Webb DR (1987) Thermal tolerance of avian embryos: a review. Condor $89: 874-898$

Wesołowski T (1996) Natural nest sites of marsh tit (Parus palustris) in a primaeval forest (Białowieża National Park, Poland). Vogelwarte $38: 235-249$

Wesołowski T (2002) Anti-predator adaptations in nesting marsh tits Parus palustris: the role of nest-site security. Ibis 144:593-601

Wesołowski T (2003) Clutch size and breeding performance of marsh tits Parus palustris in relation to hole size in a primeval forest. Acta Ornithol 38:65-72

Wesołowski T (2007) Lessons from long-term hole-nester studies in a primeval temperate forest. J Ornithol 148(Suppl 2):S395-S405

Wesołowski T, Cholewa M (2009) Climate variation and bird breeding seasons in a primeval temperate forest. Clim Res 38:199-208

Wesołowski T, Tomiałojć T (2005) Nest sites, nest depredation, and productivity of avian broods in a primeval temperate forest: do the generalisations hold? J Avian Biol 36:361-367

Wesołowski T, Czeszczewik D, Hebda G, Maziarz M, Mitrus C, Rowiński P (2015) 40 years of breeding bird community dynamics in a primeval temperate forest (Białowieża National Park, Poland). Acta Ornithol 50:95-120

Wiebe KL (2001) Microclimate of tree cavity nests: is it important for reproductive success in northern flickers? Auk 118:412-421

Willis CKR, Brigham RM (2007) Social thermoregulation exerts more influence than microclimate on forest roost preferences by a cavitydwelling bat. Behav Ecol Sociobiol 62:97-108

de Zwaan DR, Martin K (2018) Substrate and structure of ground nests have fitness consequences for an alpine songbird. Ibis 160:790-804 